\title{
Genetic Analysis of Locomotion and Associated Conformation Traits of Holstein-Friesian Dairy Cows Managed in Different Housing Systems
}

\author{
O. M. Onyiro ${ }^{1}$ and S. Brotherstone \\ School of Biological Sciences, Ashworth Laboratories, University of Edinburgh, Kings Buildings, West Mains Road, Edinburgh, \\ United Kingdom, EH9 3JT
}

\begin{abstract}
The objectives of this study were to determine the influence of housing on lameness-related linear and composite traits, and to estimate heritabilities of the traits and correlations among them. Data comprised 156,770 national type evaluation records of pedigreed first-lactation Holstein-Friesian cows that calved from 2000 through 2006 and were classified in different housing systems-cubicles, straw yards, slatted or loafing yards, and on pasture. Locomotion score (LOCO), rear leg, side view (RLS), foot angle (FA), bone quality (BONEQ), legs and feet (L\&F), and mammary composite (MAMM) were the traits measured. Data were analyzed by REML, using an animal model. In general, cows in grazing systems had better locomotion, straighter RLS, steeper FA, flat and more refined bones, better L\&F, and better mammary systems compared with cows housed in other systems. Estimates of heritability ranged from 0.11 for LOCO to 0.31 for MAMM. Bone quality had the highest heritability (0.23) of the traits associated with L\&F. Genetic associations between BONEQ and LOCO, L\&F, and MAMM were moderate to high ( 0.30 to 0.50 ), but estimates between BONEQ and RLS and FA were not significantly different from zero. Locomotion score had a very high genetic $(0.98)$ and phenotypic (0.78) correlation with L\&F, indicating that both traits are genetically the same. On the basis of the genetic parameters, including BONEQ in a selection index as a predictor of longevity is promising, but further information on its association with longevity is required.
\end{abstract}

Key words: genetic analysis, locomotion, conformation, housing system

\section{INTRODUCTION}

The main emphasis in dairy cattle improvement is to increase profit by breeding high-yielding healthy cows

Received July 10, 2007.

Accepted September 21, 2007.

${ }^{1}$ Corresponding author: o.m.onyiro@sms.ed.ac.uk with sound feet and legs. Locomotive traits have been shown to affect longevity and hence profit (Booth et al., 2004; Esslemont, 1990), and most countries include traits associated with feet and legs in their national selection index (Miglior et al., 2005).

Environmental variability in locomotion traits is associated with differences in management and housing systems (Broom, 1990; Esslemont, 1990). Bergsten (2004) reported that floors in intensive farming systems are mostly made of nonyielding concrete, which gets slippery over time, and manure contamination is widespread; the result of this is increased locomotion disorders. Studies have reported an increased prevalence of hoof lesions with solid concrete floors compared with straw yards (Webster, 2002; Somers et al., 2003). Similar results were observed with solid concrete floors vs. slatted concrete floors (Frankena et al., 1992) and solid concrete floors vs. rubber slats (Hultgren and Bergsten, 2001). In the United Kingdom, information on housing type and flooring quality is routinely collected at the same time the cows are type-classified, providing the opportunity to estimate associations among type traits and housing by using national data.

On the basis of genetic correlations of clinical lameness with type traits, Boettcher et al. (1998) suggested that foot angle, rear leg set, and rump width could provide an indication of susceptibility to locomotion problems. Old age, deep udders, sickled legs, and long hoof diagonals have also been associated with locomotion problems in cows (Boelling and Pollot, 1998).

Several studies have estimated genetic parameters for locomotion traits for inclusion into lifetime economic merit indices (Weigel et al., 1998; Stott et al., 2005). In the United Kingdom, recording of type traits dates back more than $20 \mathrm{yr}$, and a trait describing the locomotion of animals was introduced $10 \mathrm{yr}$ ago. Although estimates of heritabilities and genetic correlations among linear and miscellaneous type traits (Brotherstone et al., 1990), as well as among type and production traits (Brotherstone, 1994), have been reported for UK Holstein-Friesian cows, as yet no genetic associations of locomotion with other type traits have been published. Bone quality (BONEQ) is a new trait in the UK type 
classification scheme and is not routinely classified in many other countries. As a result, little information is available in the literature on the genetic and phenotypic relationships of BONEQ with other type traits, in particular type traits associated with longevity. Bone quality is measured on a linear scale from thick and coarse bone to flat and refined bone. Gordon and Shannon (2002) reported that BONEQ is an indication of fitness and good circulation through the legs and has a strong positive genetic correlation with dairy character and milk production. Flat- and fine-boned cows will walk better as a result of decreased bone mass and reduced surface area of contact, particularly at the hock joints, which could minimize leg problems. Dekkers et al. (1994) reported that BONEQ had a moderate genetic association with longevity.

The aims of this research were 1) to determine the influence of housing system on linear and composite type traits related to lameness in Holstein-Friesian dairy cows, 2) to estimate the heritability of locomotion and its genetic correlation with other traits related to legs and feet, and 3) to investigate whether BONEQ is a useful type trait to collect, particularly with respect to its genetic association with locomotive problems.

\section{MATERIALS AND METHODS}

\section{Data}

Data were those used for UK national type evaluations. The data set consisted of 156,770 type classification records of pedigreed first-lactation Holstein-Friesians calving from 2000 through 2006. The reason for not including records prior to 2000 is that collection of housing information began that year.

The type traits involved in the analysis were the linear traits locomotion score (LOCO), rear leg, side view (RLS), and foot angle (FA), the overall subjective type traits legs and feet $(\mathbf{L} \boldsymbol{\&} \mathbf{F})$ and mammary composite (MAMM), and BONEQ. Mammary composite, which is highly correlated with linear traits describing udder conformation, was included because many of the udder traits have been shown to be associated with clinical lameness (Boettcher et al., 1998). The linear traits are scored from 1 to 9 , where 1 and 9 represent biological extremes, and the composite traits are scored from 65 to 95 , which represents a continuum on a scale from "poor" to "excellent." A brief description of the traits is given in Table 1, whereas the locomotion scoring system used for the national herds is defined in Table 2.

Cows were between 19 and 50 mo of age at inspection. Herds were visited a maximum of once every 10 mo to avoid classifying animals more than once per lactation.

\section{Housing Information}

Three pieces of housing information were routinely collected by the field officers: 1) Housing type-cows were recorded as being housed in 1 of 4 different categories of housing: cubicles, straw yards, on pasture, and others (slatted and loafing yards). 2) Time spent in housing - the amount of time the animal had spent in a particular type of housing was recorded. This allowed us to differentiate between (for example) an animal that had spent a month on pasture and one that had been on pasture for $4 \mathrm{mo}$. 3) Floor condition at classificationthe condition of the farm flooring on which the type classification took place was graded from 1 to 5 , depending on how slippery and even the flooring was. A poor flooring condition (floor 1) was characterized by slippery, dirty surfaces and holes in the concrete, whereas the ideal condition (floor 5) denoted nonslippery, clean, and level surfaces. Although this assessment was based on the floor where the cows were classified, we would expect this floor condition to be related to the floor condition on all parts of the farm and also to be related to the overall management of the dairy. Evaluation of the flooring by scorers was subjective. The numbers of cows scored on floor conditions 1, 2, 3 , 4, and 5 were $25,284,4,894,15,408,32,491$, and 78,693 , respectively.

\section{Statistical Analysis}

Analysis was by univariate REML, using an animal model. The pedigree file comprised 309,881 animals. Because of the small number of animals spending 6 or more months in a particular type of housing, the amount of time in a particular housing type was reclassified as 1, 2, 3, 4, or 5 mo and then 6 or more. Similarly, few animals were recorded in slatted or loafing yards, so no account of the amount of time in this housing type was made. The total numbers of cows classified in cubicles, straw yards, on pasture, and in slatted or loafing yards were $97,511,8,535,49,655$, and 1,069, respectively. A preliminary analysis indicated that housing type, month in housing, and their interaction removed a significant amount of variation in the type traits, so in the final model, months in housing was nested within housing type. We will refer to this combined effect as the housing situation. Herd-year-visit was included as a random effect because it was confounded with floor condition.

The mixed-model equation used to describe the data is

$$
\begin{gathered}
Y_{i}=\mu+\text { hyv }+\sum_{n=1}^{2} \chi_{n} \text { age }^{n}+\sum_{n=1}^{2} \beta_{n} \text { stage }^{n} \\
+\delta . p h o l s+\text { moc }+ \text { hfloor }+ \text { hcode.hmns }+ \text { anim }_{i}+e_{i},
\end{gathered}
$$


Table 1. Description of type traits considered in the analyses

\begin{tabular}{|c|c|c|c|c|c|c|}
\hline \multirow[b]{2}{*}{ Type trait } & \multirow[b]{2}{*}{ Abbreviation } & \multirow[b]{2}{*}{ Description } & \multicolumn{2}{|c|}{ Score } & \multirow[b]{2}{*}{ Mean } & \multirow[b]{2}{*}{$\mathrm{SD}$} \\
\hline & & & 1 & 9 & & \\
\hline Locomotion & LOCO & Walking potential & Lame & Normal & 5.37 & 1.42 \\
\hline Foot angle & FA & $\begin{array}{l}\text { Angle at the front of rear } \\
\text { hoof from base to hairline }\end{array}$ & Low & Steep & 5.15 & 1.38 \\
\hline \multirow[t]{3}{*}{ Bone quality } & BONEQ & $\begin{array}{l}\text { Degree of flatness or fineness } \\
\text { of the bone }\end{array}$ & Thick and coarse & Flat and refined & 6.18 & 1.31 \\
\hline & & & \multicolumn{2}{|c|}{ Composite score } & & \\
\hline & & & 65 & 95 & & \\
\hline Leg and feet composite & $\mathrm{L} \& \mathrm{~F}$ & $\begin{array}{l}\text { Combination of all traits } \\
\text { and mobility }\end{array}$ & Poor & Excellent & 79.74 & 5.06 \\
\hline Mammary composite & MAMM & $\begin{array}{l}\text { Combination of all traits } \\
\text { relating to udder and teat } \\
\text { positioning }\end{array}$ & Poor & Excellent & 79.98 & 5.17 \\
\hline
\end{tabular}

where $Y_{i}$ is the type trait measurement on animal $\mathrm{i}, \mu$ is the overall mean, hyv is the herd-year-visit group where animal $i$ was measured, $\chi_{1}$ and $\chi_{2}$ are the linear and quadratic regression coefficients of traits on the age of animal $i$ at inspection, $\beta_{1}$ and $\beta_{2}$ are the linear and quadratic regression coefficients of traits on stage of lactation (stage) of animal $i$ at inspection, $\delta$ is the linear regression of traits on the proportion of Holstein genes (phols) in the animal, moc is the month of calving of the animal, $h$ floor is the floor condition when animal $i$ was inspected, hcode.hmns is the housing situation (type of housing and time spent in each type of housing), anim $_{i}$ is the random genetic effect of the animal, and $e_{i}$ is the residual random error.

To account for differences in the range of scoring used by the field officers, each trait was first scaled by the ratio of the standard deviation of the classifier to the mean standard deviation of all classifiers (Brotherstone, 1994). Heritability for each trait was calculated from cow and residual variance components.

Estimation of genetic correlations between BONEQ, LOCO, and the other traits was by multiple-trait REML in an animal model. For computing convenience, the analysis involved a subset of the original data comprising 37,065 type classification records of cows type-classified from the beginning of 2005. Even with the reduced data set, a multivariate analysis with all 6 traits was not possible because of computing difficulties, so 2 -trait analyses (i.e., 9 bivariate analyses in total) were performed with BONEQ and each of the other 5 traits in turn, as well as with LOCO and each of the 4 remaining traits. All analyses were carried out by using ASREML software (Gilmour et al., 2000).

\section{RESULTS}

\section{Housing Effect}

In general, the covariates (mean proportion of Holstein genes, age of cow at inspection, and stage of lactation at inspection) and month of calving were significant $(P<0.05)$. Results from the ANOVA showed that the effect of housing situation was significant $(P<0.05)$ for all traits. Predicted effects of the housing situation on the type traits are given in Table 3 . Results presented are for $5 \mathrm{mo}$ in a particular housing type and are relative to 5 mo on pasture. Results are similar irrespective of

Table 2. Descriptions of locomotion scores

\begin{tabular}{ll}
\hline Locomotion score & \multicolumn{1}{c}{ Description } \\
\hline 1 & Lame \\
2 & Severe abduction or adduction present, uneven gait, short strides \\
3 & Abduction or adduction present, uneven gait \\
4 & Slight abduction or adduction present, even gait, short strides \\
5 & No abduction or adduction present, even gait, short strides \\
6 & Slight abduction or adduction present, even gait, medium strides \\
7 & Slight abduction or adduction present, even gait, long strides \\
8 & No abduction or adduction present, even gait, medium strides \\
9 & No abduction or adduction present, even gait, long strides \\
\hline
\end{tabular}


Table 3. Predicted effects $\pm \mathrm{SE}$ of the housing system on type traits relative to cows housed on pasture

\begin{tabular}{lrrrrrr}
\hline & \multicolumn{5}{c}{ Trait $^{1}$} \\
\cline { 2 - 7 } Housing situation & \multicolumn{1}{c}{ LOCO } & \multicolumn{1}{c}{ RLS } & FA & BONEQ & L\&F \\
\hline Cubicle & $-0.12^{*} \pm 0.03$ & $0.05 \pm 0.03$ & $0.12^{*} \pm 0.03$ & $-0.21^{*} \pm 0.03$ & $-0.53^{*} \pm 0.11$ \\
Straw yard & $-0.22^{*} \pm 0.07$ & $0.59^{*} \pm 0.10$ & $-0.42^{*} \pm 0.06$ & $-0.03 \pm 0.07$ & $-1.36^{*} \pm 0.23$ & $-0.19 \pm 0.10$ \\
Slatted floor or loafing yard & $-0.02 \pm 0.09$ & $-0.27^{*} \pm 0.08$ & $-0.01 \pm 0.08$ & $0.08 \pm 0.09$ & $-0.85^{*} \pm 0.30$ & $-0.19 \pm 0.21$ \\
\hline &
\end{tabular}

the number of months in a particular housing type. Compared with cows on pasture, cows housed in the 3 housing systems had significantly poorer scores for overall $\mathrm{L} \& \mathrm{~F}(P<0.05)$. Cubicle housing was also associated $(P<0.05)$ with poorer locomotion and lower BONEQ scores. Locomotion score, RLS, FA, and MAMM scores of cows in straw yards were significantly lower $(P<0.05)$ compared with the scores of cows on pasture, indicating that cows are also more susceptible to locomotive disorders in straw yards than on grass. The BONEQ of cows in straw-bedded yards did not differ significantly from the BONEQ of cows on pasture. Cows kept in loafing yards, on slatted floors, or both had straighter RLS and poorer L\&F compared with cows on pasture. Generally, the results indicate that cows on pasture had fewer locomotive disorders than cows in other types of housing.

The quality of flooring removed a significant $(P<$ 0.05 ) amount of variation for all the traits measured. Table 4 gives the influence of flooring condition on the traits. Predicted values are relative to poor flooring condition. Cows classified on floor conditions 4 and 5 had significantly $(P<0.05)$ better scores for L\&F than those classified on floor conditions 1 to 3 . Cows scored on floor condition 4 had significantly $(P<0.05)$ better LOCO, straighter RLS, steeper FA, and more flat and refined BONEQ compared with cows scored on the poor- est floor condition. A reduced score for BONEQ was linked to floor condition 5, and MAMM was highest for cows type-classified on the poorest floor conditions. This association is not intuitive and cannot be explained.

\section{Genetic Parameters}

Heritability estimates $\left(\mathbf{h}^{2}\right)$ for all type traits, genetic $\left(\mathbf{r}_{\mathbf{g}}\right)$ and phenotypic $\left(\mathbf{r}_{\mathbf{p}}\right)$ correlations among BONEQ, LOCO, and the other traits, and standard errors are shown in Table 5. The heritabilities ranged from 0.11 for LOCO to 0.31 for MAMM. Heritability of BONEQ (0.23) was higher than the values for the other traits associated with L\&F.

Phenotypic correlations with BONEQ were positive and, in general, were smaller in magnitude than the genetic correlations. Genetic correlations of BONEQ with $\mathrm{LOCO}, \mathrm{L} \& \mathrm{~F}$, and MAMM were moderate to high (0.30 to 0.50), an indication that finer BONEQ is associated with better locomotion and a superior mammary system. Genetic associations of BONEQ with FA and RLS were not significantly different from zero.

Phenotypic correlations of LOCO with the type traits were generally positive and lower in magnitude than the corresponding genetic relationships. Locomotion score had moderate genetic correlations with FA and MAMM, suggesting that steeper FA and well-fitted

Table 4. Predicted effects \pm SE of flooring condition on the locomotion type traits relative to a flooring condition score $1^{1}$

\begin{tabular}{|c|c|c|c|c|c|c|}
\hline \multirow{2}{*}{$\begin{array}{l}\text { Flooring } \\
\text { condition }\end{array}$} & \multicolumn{6}{|c|}{ Trait $^{2}$} \\
\hline & LOCO & RLS & FA & BONEQ & $\mathrm{L \& F}$ & MAMM \\
\hline 2 vs. 1 & $-0.05 \pm 0.04$ & $-0.11^{*} \pm 0.04$ & $-0.05 \pm 0.04$ & $-0.31^{*} \pm 0.05$ & $-0.48^{*} \pm 0.15$ & $-0.77^{*} \pm 0.14$ \\
\hline 3 vs. 1 & $0.04 \pm 0.03$ & $-0.10^{*} \pm 0.03$ & $0.06^{*} \pm 0.03$ & $-0.26^{*} \pm 0.03$ & $-0.16 \pm 0.11$ & $-0.56^{*} \pm 0.10$ \\
\hline 4 vs. 1 & $0.23^{*} \pm 0.03$ & $-0.13^{*} \pm 0.04$ & $0.11^{*} \pm 0.02$ & $0.14^{*} \pm 0.03$ & $0.57^{*} \pm 0.09$ & $-0.52 * \pm 0.08$ \\
\hline 5 vs. 1 & $0.09 * \pm 0.02$ & $0.002 \pm 0.02$ & $0.05^{*} \pm 0.02$ & $-0.08^{*} \pm 0.03$ & $0.58^{*} \pm 0.08$ & $-0.47^{*} \pm 0.08$ \\
\hline
\end{tabular}

${ }^{1}$ Flooring condition scored as 1 = slippery, dirty surfaces with holes in concrete; $2=$ even concrete, but slippery underfoot; 3 = uneven or sloping concrete; $4=$ level concrete; $5=$ perfect nonslippery, clean and level surfaces.

${ }^{2} \mathrm{LOCO}=$ locomotion score; $\mathrm{RLS}=$ rear leg, side view; FA = foot angle; $\mathrm{BONEQ}$ = bone quality; $\mathrm{L} \& \mathrm{~F}=$ leg and feet composite; MAMM = mammary composite.

$* P<0.05$. 
Table 5. Heritabilities $\left(h^{2}\right)$ of type traits and genetic $\left(r_{g}\right)$ and phenotypic $\left(r_{p}\right)$ correlations of bone quality with other conformation traits and locomotion score and of locomotion score with conformation traits together with SE

\begin{tabular}{|c|c|c|c|c|c|c|}
\hline Type trait $^{1}$ & $\mathrm{~h}^{2}$ & $\mathrm{SE}\left(\mathrm{h}^{2}\right)$ & $r_{g}$ & $\mathrm{SE}\left(\mathrm{r}_{\mathrm{g}}\right)$ & $r_{p}$ & $\mathrm{SE}\left(\mathrm{r}_{\mathrm{p}}\right)$ \\
\hline BONEQ & 0.23 & 0.010 & & & & \\
\hline LOCO & 0.11 & 0.007 & 0.50 & 0.076 & 0.26 & 0.006 \\
\hline RLS & 0.15 & 0.008 & 0.08 & 0.084 & 0.00 & 0.006 \\
\hline FA & 0.11 & 0.007 & -0.10 & 0.086 & 0.03 & 0.006 \\
\hline $\mathrm{L} \& \mathrm{~F}$ & 0.18 & 0.009 & 0.50 & 0.067 & 0.33 & 0.006 \\
\hline MAMM & 0.31 & 0.011 & 0.30 & 0.068 & 0.22 & 0.007 \\
\hline \multicolumn{7}{|l|}{ LOCO } \\
\hline RLS & - & - & -0.26 & 0.099 & -0.16 & 0.006 \\
\hline FA & - & - & 0.30 & 0.099 & 0.20 & 0.005 \\
\hline $\mathrm{L} \& \mathrm{~F}$ & - & - & 0.98 & 0.008 & 0.78 & 0.002 \\
\hline MAMM & - & - & 0.48 & 0.076 & 0.23 & 0.006 \\
\hline
\end{tabular}

${ }^{1} \mathrm{LOCO}=$ locomotion score; RLS = rear leg, side view; FA = foot angle; $\mathrm{BONEQ}=$ bone quality; $\mathrm{L} \& \mathrm{~F}=$ leg and feet composite; MAMM = mammary composite.

mammary systems are associated with better locomotion. Locomotion score and L\&F were highly genetically (0.98) and phenotypically (0.78) correlated. A similar result has been found by other researchers (S. Brotherstone, unpublished data; van der Waaij et al., 2005). The genetic association between LOCO and RLS was negative, which indicates that sickled hocks are associated with poorer locomotion.

\section{DISCUSSION}

\section{Effect of Housing on Locomotive Traits}

Reported associations among linear and composite type traits and different housing systems are scarce in the literature. However, significant differences in mean phenotypic scores of type traits (heel depth; FA; RLS; rear leg, rear view; BONEQ; and overall L\&F) between free-stall and tie-stall housing systems have been reported (Fatehi et al., 2003).

Our results show that, in general, cows on pasture had higher linear scores and better composite scores compared with cows in other housing systems. Studies have reported reduced claw disorders in cows on pasture compared with cows in other housing systems (Frankena et al., 1991; Somers et al., 2003). In smallscale Kenyan herds, Gitau et al. (1996) found that cows with access to grazing had a reduced risk of lameness compared with those with no access to grazing. The better L\&F and fewer locomotive problems found in cows on grass could be attributed to the fact that grass is a softer environment for lying and rising. This continues to underline the importance of softer housing environments for reducing the incidence of claw and locomotion problems. Fregonesi (1999) showed that dairy cows preferred standing on soft surfaces (straw yards) rather than on concrete floors (cubicle systems). Results obtained from the analysis of flooring condition (Table 4) indicate that well-managed, nonslippery, and level floor surfaces minimize locomotion disorders.

\section{Genetic Analysis}

Heritability. The type traits associated with L\&F had genetic components of variation significantly greater than zero and were low to moderately heritable. In general, the heritability of LOCO $\left(\mathrm{h}^{2}=0.11\right)$ is in agreement with previous estimates $\left(h^{2}=0.10\right)$ for Holstein-Friesian dairy cows (Stott et al., 2005; van der Waaij et al., 2005). Heritabilities for RLS, FA, and L\& $\mathrm{F}$ were slightly lower than earlier reports. With a sire model, Brotherstone (1994) obtained heritability estimates of $0.19,0.27$, and 0.32 , whereas van der Waaij et al. (2005) reported estimates of $0.22,0.18$, and 0.24 , respectively, for the traits. The heritabilities of BONEQ and L\&F in our study are consistent with the results of Fatehi et al. (2003), who reported a range of 0.24 to 0.29 for BONEQ and 0.15 to 0.17 for L\&F in free-stall vs. tie-stall environments. Van Dorp et al. (2004), in a study of the genetics of locomotion, estimated a heritability of 0.30 for BONEQ in Canadian Holsteins. Our heritability estimate for BONEQ (0.23) suggests that direct selection for flat and refined bone in dairy cows could be moderately successful.

Correlations of BONEQ with Linear and Composite Traits. Results from the multivariate analysis indicate moderate genetic associations between BONEQ and both LOCO and L\&F. This is not surprising because these traits describe a general assessment of the L\&F. The results indicate that selection for good mobility, good L\&F, or both would lead to improvement in BONEQ and vice versa. According to Rogers (1996), selecting for improved BONEQ may be useful for improving leg traits. Van Dorp et al. (2004) estimated a moderate genetic correlation of 0.25 between BONEQ 
and locomotion and reported that BONEQ might be affected by poorly designed stalls. In an analysis of QTL affecting lameness and leg conformation traits, Buitenhuis et al. (2007) reported a moderate genetic correlation (-0.49) between lameness and BONEQ in Danish Holstein dairy cattle and concluded that lameness could be reduced by increasing the frequency of the superior QTL genotype for BONEQ. Our result is in agreement with the result of this genomic study showing that locomotion could be improved by selecting for improved BONEQ.

The estimated genetic correlation of 0.30 between BONEQ and MAMM suggests that cows with flat and refined bones are more likely to have well-attached and rounded udders.

Considering the moderate heritability estimate of BONEQ and its high genetic association with LOCO, breeding for flatter, more refined BONEQ seems a promising method of reducing locomotion problems and thereby increasing dairy cow longevity. In the United Kingdom, an index of 3 type traits-foreudder attachment, L\&F composite, and MAMM-is used together with SCC in a phenotypic prediction of longevity, and is included in the national genetic evaluations for longevity as a correlated trait (Brotherstone et al., 1998). Including BONEQ in this index may improve its accuracy. However, an investigation to estimate the association of BONEQ with longevity is needed.

No significant genetic relationship was found between BONEQ and both RLS and FA. This is surprising because FA and RLS had moderate genetic correlations with LOCO, which had a high genetic association with BONEQ. A possible explanation is the existence of a nonlinear relationship between these traits. To investigate this, residuals for FA and RLS were regressed on residuals for BONEQ. The results (not shown) indicated a significant linear but nonsignificant quadratic association between BONEQ and the 2 traits.

The phenotypic correlations between BONEQ and LOCO, FA, L\&F, and MAMM imply that, phenotypically, cows with fewer locomotive problems, a steeper FA, a high L\&F score, and a superior mammary system had flatter, more refined bones.

Correlations Between LOCO and the Other Traits. The moderate genetic associations of LOCO with FA and MAMM imply that cows with low FA and sagging or pendulous udders are most likely to suffer lameness. Boettcher et al. (1998) obtained strong but negative genetic correlations between FA and clinical lameness from linear (-0.76) and threshold $(-0.64)$ models, and concluded that a flatter FA is genetically associated with increased clinical lameness. The negative genetic correlation between locomotion and RLS suggests that cows with a straight leg set will have improved walking ability.

The tight genetic relationship between LOCO and L\&F strongly suggests that the same genes control both traits. Thus, sound locomotion is closely associated with good L\&F. Paget et al. (2003) reported a high genetic correlation of 0.91 between locomotion and the L\&F composite for UK Guernseys. In the Netherlands, van der Waaij et al. (2005) reported a genetic and phenotypic correlation of 0.98 and 0.85 , respectively, between LOCO and L\&F for Dutch Holstein-Friesian dairy cows. Classifiers consider mobility while evaluating L\&F, so a high genetic association between the 2 traits is expected.

The negative phenotypic correlation between LOCO and RLS indicates that, phenotypically, cows with good locomotion have straighter legs. The associations between LOCO and FA and MAMM suggest that cows with steeper FA and better mammary systems are phenotypically predisposed to better locomotion. Phenotypically, the strong association of LOCO with L\&F is evidence that cows with good L\&F scores had better mobility.

\section{CONCLUSIONS}

Cows on pasture had favorable type trait scores compared with cows in other housing systems. Nonslippery, level floor surfaces were associated with fewer locomotion problems and better L\&F. Locomotion had a high genetic correlation with L\&F and a moderate genetic association with FA and MAMM, indicating that cows with higher scores for L\&F and MAMM and with steeper FA had genetically better locomotion. The moderate and positive genetic associations between $\mathrm{BO}$ NEQ and LOCO and L\&F suggest that selection for flat and refined bones will result in improved locomotion. Bone quality is moderately heritable.

\section{ACKNOWLEDGMENTS}

We would like to thank Holstein-UK (Rickmansworth, UK) for supplying us with the national data and the field officers for collecting the information on housing. Thanks also to Ian White for help with software.

\section{REFERENCES}

Atkins, G., and J. Shannon. 2002. Minimizing lameness through genetic selection. www. wcds.afns.ualberta.ca/proceedings/2002

Bergsten, C. 2004. Healthy feet requires cow comfort 24 hours. Pages 186-191 in Proc. 13th Int. Symp. 5th Conf. Lameness in Rumin., Maribor, Slovenija. B. Zemljic, ed. Maribor, Slovenia.

Boelling, D., and G. E. Pollot. 1998. Locomotion, lameness, hoof and leg traits in cattle. II. Genetic relationships and breeding values. Livest. Prod. Sci. 54:205-215. 
Boettcher, P. J., J. C. Dekkers, L. D. Warnick, and S. J. Wells. 1998. Genetic analysis of clinical lameness in dairy cattle. J. Dairy Sci. 81:1148-1156.

Booth, C. J., L. D. Warnick, Y. T. Grohn, D. O. Maizon, C. L. Guard, and D. Janssen. 2004. Effect of lameness on culling in dairy cows. J. Dairy Sci. 87:4115-4122.

Broom, D. M. 1990. The importance of measures of poor welfare. Behav. Brain Sci. 13:14.

Brotherstone, S. 1994. Genetic and phenotypic correlations between linear type traits and production traits in Holstein-Friesian dairy cattle. Anim. Prod. 59:183-187.

Brotherstone, S., C. M. McManus, and W. G. Hill. 1990. Estimation of genetic parameters for linear and miscellaneous type traits in Holstein-Friesian dairy cattle. Livest. Prod. Sci. 26:177-192.

Brotherstone, S., R. F. Veerkamp, and W. G. Hill. 1998. Predicting breeding values for herd life of Holstein-Friesian dairy cattle from lifespan and type. Anim. Sci. 87:405-411.

Buitenhuis, A. J., M. S. Lund, J. R. Thomasen, B. Thomsen, V. Hunnicke Nielsen, C. Bendixen, and B. Guldbrandtsen. 2007. Detection of quantitative trait loci affecting lameness and leg conformation traits in Danish Holstein cattle. J. Dairy Sci. 90:472-481.

Dekkers, J. C. M., L. K. Jairath, and B. H. Lawrence. 1994. Relationships between sire genetic evaluations for conformation and functional herd life of daughters. J. Dairy Sci. 77:844-854.

Esslemont, R. 1990. The costs of lameness in dairy herds. Page 237251 in VIth Int. Symp. Dis. Rumin. Digit. Br. Cattle Vet. Assoc., Liverpool, UK.

Fatehi, J., A. Stella, J. J. Shannon, and P. J. Boettcher. 2003. Genetic parameters for feet and leg traits evaluated in different environments. J. Dairy Sci. 86:661-666.

Frankena, K., E. N. Stassen, J. P. Noordhuizen, J. O. Goelema, J. Schipper, H. Smelt, and H. Romkema. 1991. Prevalence of lameness and risk indicators for dermatitis digitalis during pasturing and housing of dairy cattle. Pages 107-118 in Proc. Ann. Symp. Soc. Vet. Epidemiol. Prev. Med., London, UK. G. J. Rowlands, ed.

Frankena, K., K. A. S. van Keulen, J. P. Noorhuizen, E. N. Noordhuizen-Stassen, J. Gundelach, D. J. de Jong, and I. Saedt. 1992. A cross-section study into prevalence and risk indicators of digital haemorrhages in female dairy calves. Prev. Vet. Med. 14:1-12.
Fregonesi, J. A. 1999. Production and behaviour of dairy cattle in different housing systems. PhD Diss. Univ. London, UK.

Gilmour, A. R., B. R. Cullis, S. J. Welham, and R. Thompson. 2000. ASREML Reference Manual. Orange Agric. Inst., New South Wales, Australia.

Gitau, T., J. J. McDermott, and S. M. Mbiuki. 1996. Prevalence, incidence, and risk factors for lameness in dairy cattle in small scale farms in Kikuyu Division, Kenya. Prev. Vet. Med. 28:101-115.

Hultgren, J., and C. Bergsten. 2001. Effects of a rubber-slatted flooring system on cleanliness and foot health in tied dairy cows. Prev. Vet. Med. 52:75-89.

Miglior, F., B. L. Muir, and B. J. Van Doormaal. 2005. Selection indices in Holstein cattle of various countries. J. Dairy Sci. 88:1255-1263.

Paget, M. F., G. J. T. Swanson, and R. A. Mrode. 2003. Genetic parameters for locomotion and composite type traits for the Jersey and Guernsey dairy breeds in the United Kingdom (UK). Page 53 in Proc. Annu. Conf. Br. Soc. Anim. Sci., York, UK. Br. Soc. Anim. Sci., UK.

Rogers, G. W. 1996. Using type for improving health of the udder and feet and legs. Interbull Bull. 12:33-41.

Somers, J. G. C. J., K. Frankena, E. N. Noordhuizen-Stassen, and J. H. M. Metz. 2003. Prevalence of claw disorders in Dutch dairy cows exposed to several floor systems. J. Dairy Sci. 86:2082-2093.

Stott, A. W., M. P. Coffey, and S. Brotherstone. 2005. Including lameness and mastitis in a profit index for dairy cattle. Anim. Sci. 80:41-52.

van der Waaij, E. H., M. Holzhauer, E. Ellen, C. Kamphuis, and G. de Jong. 2005. Genetic parameters for claw disorders in Dutch dairy cattle and correlations with conformation traits. J. Dairy Sci. 88:3672-3678.

Van Dorp, T. E., P. Boettcher, and L. R. Schaeffer. 2004. Genetics of locomotion. Livest. Prod. Sci. 90:247-253.

Webster, A. J. 2002. Effects of housing practices on the development of foot lesions in dairy heifers in early lactation. Vet. Rec. 152:351-358.

Weigel, K. A., T. J. Tawlor, Jr., M. P. Vanraden, and G. R. Wiggans. 1998. Use of linear type and production data to supplement early predicted transmitting abilities for productive life. J. Dairy Sci. 81:2040-2044. 